\title{
Evaluation of the Parameters Affecting the Seismic Response of Railway Bridges with Reinforced Concrete Box Deck
}

\author{
Moein Zargar*1, Mohammad Ali Rahgozar ${ }^{2}$ \\ ${ }^{1}$ Civil engineering department, Farzanegan Institute of Higher Education \\ ${ }^{2}$ Department of Civil Engineering, Faculty of Engineering, University of Isfahan, Hezar Jerib Ave., Isfahan, \\ Iran
}

*Corresponding Author: Moein Zargar, 1Civil engineering department, Farzanegan Institute of Higher Education, Iran

\begin{abstract}
Examining the statistics of the General Directorate of Railways and Technical Structures of the Railway, it can be said that by the end of 1397, there were 28984 bridges in the country\&\#39; railway network, of which 223 bridges were made of concrete boxes. Due to the advantages of these bridges, it is possible to use this type of bridge in more projects. Increasing the use of concrete box bridges requires more research and considering all aspects of design and implementation of such bridges. In this study, the dynamic modeling of railway bridges with reinforced concrete box deck has been discussed. For this purpose, three bridges with different base heights and also three bridges with different number of openings have been selected. Then, the limited components of the mentioned steps in Abacus software are modeled. In order to simulate the conditions of earthquake loading, El Centro seismic mapping acceleration has been used. Also, the standard loading of the magazine No. 139 of the Management and Planning Organization of the IRAN (the rules of loading the bridges) has been used in order to apply the train load. Finally, the effect of the height of the bridge pedestals as well as the number of openings on the relative displacement and period of the study structure was investigated using finite element method and Abacus software. The results show that increasing the number of openings will increase the maximum displacement rate of bridges. Also, with increasing number of openings in all vibration modes, the structural period increases. On the other hand, increasing the height of the pedestals increases the amount of displacement of the bridge, in addition as the height of the bridge pedestals increases, the amount of the bridge period increase.
\end{abstract}

\section{INTRODUCTION}

Due to the high risk of earthquakes in Iran and the existence of many faults near many cities in Iran, the probability of earthquakes in the near field with a significant vertical component is high. Among all kinds of facilities, the bridges are undoubtedly one of the vital arteries that need to be used after the earthquake as a way to access hospitals, fire stations and other crisis services. Damage or destruction of bridges in a severe earthquake results in a lack of access to emergency services, loss of life and long- term interruptions in the transportation system. In the following, some previous researches that have appropriate research topics will be mentioned and their results will be stated.

In 2017, Pahlavan et al. investigated the sensitivity of the number of openings in seismic dynamic behavior of multi-frame bridges of reinforced concrete box deck decks. The effect of the number of openings in the seismic response of arched bridge decks of reinforced concrete box deck in this study was investigated. For this purpose, reinforced concrete bridge model with different number of openings with circular multi-column bases was performed. The main parameter of the model is the number of bridge openings. Thus, three bridge models, including a four-span bridge as a base model and two bridges of three and five spans, respectively, were modeled. A set of seven earthquake records was considered, and for each of the three states, the number of openings was applied and the models were analyzed by analyzing the nonlinear time history. The results of this study have shown that the number of openings is an important and influential parameter on the extent of damage to bridges in the study class. In this study, the maximum values of column drifts are presented in both longitudinal and transverse directions. It is observed that increasing the number of openings reduces the maximum relative displacement of the bridge and subsequently reduces the amount of damage to the bridge [1]. 
In 2004, Tahouni et al. investigated the distortion of the deck of concrete box bridges. In this paper, the distortion of box decks has been studied and the studies conducted in this field have been introduced. Ansys 6.1 Limited Components Software has been used to analyze the distortion of box decks. The model of limited components of Ahvaz Concrete Box Bridge has been made entirely with the help of this software, and the approximate analysis of the distortion of the mentioned throne has been done using Sap 2000 software. The results of the finite element method have been compared with the approximation method and it has been shown that the approximate proposed method has the appropriate accuracy. It has also been shown that box distortion has a significant effect on the shear current due to torsional forces, the angle of rotation of bridge bridges, and the distribution of transverse flexural anchors along bridge bridges [2].

In 1398, Sayadpour et al. Investigated and analyzed the sensitivity of the seismic response of a concrete bridge with a box deck to geometric and mechanical characteristics. In this study, the effect of different geometric and mechanical parameters on the seismic response of concrete bridges with box deck has been investigated. For this purpose, a nonlinear three-dimensional model of a concrete bridge was created by considering the interaction of soil and structure and its response was investigated under the effect of selected earthquakes. Sensitivity analysis performed on the results of history analyzes shows that the parameters of mass distribution, steel yield strength, compressive strength of concrete and damping have the greatest impact on the seismic behavior of such steps and therefore should be analyzed at different stages. The necessary design, construction and installation of these steps should be done in order to prevent the occurrence of uncertainties affecting these parameters [3].

In 1398, Zarfam et al. investigated the effect of earthquake angle on the performance of box deck bridges with unequal bases. In each of these studies, the effect of the impact angle of the seismic components on the engineering demand created in the bridge with unequal bases has been investigated. Accordingly, a set of four different classes of bridges are modeled with concrete box decks. In the modeling, uncertainties including materials, bridge elements, opening length, base height, and bridge width have been considered. A set of accelerometers is applied to the models at different angles, and in response to the earthquake at each angle, the response axes on the rotating plate are given to calculate the most critical demand created in the engineering parameters of the models. Based on the answers obtained from the analysis of the above nonlinear time history that has been done in OpenSees software, the fragility curves have been drawn to determine the probability of the elements reaching the failure level and the results have been examined, then to compare the results. The median fragility of engineering parameters has been compared under different collision angles for all four bridge classes introduced in this study [4].

In 2014, Khair al-Din et al. Studied and optimally designed the deck of prefabricated concrete bridges of the box according to the loading regulations of Iran Bridge using the genetic algorithm. In this paper, the optimization of the deck of pre-stretched box-reinforced concrete bridges is examined according to the loading regulations of Iran Bridge. Decreasing the weight of the bridge deck, in addition to saving on consumables and thus the cost of superstructures and substructures, has a significant effect on reducing the seismic force on the bridge. In this optimization, various variables such as the dimensions of the various components of the deck cross section, the number of tendons, the number of cables of each tendon, the arrangement of the tendons, the ratio of the tensile reinforcement of the upper slab and slab and the amount of jack traction are considered. The characteristic constraints on these variables are based on the practical conditions of construction and the limitations of the regulations. Implicit design constraints are also formulated according to AASHTO standard. Due to the fact that most constraints are nonlinear, we are faced with a nonlinear optimization problem that has different local minimums; for this reason, there is a need for a method that is able to identify at least the overall function of the target. In this paper, genetic algorithm (GA) is used for optimization. This algorithm has considerable ability to solve complex optimization problems for which classical methods are either not applicable or unreliable in finding the overall 
Evaluation of the Parameters Affecting the Seismic Response of Railway Bridges with Reinforced Concrete Box Deck

optimization. The results of this optimization show that with a one-time formulation of the bridge design problem and with the help of the genetic algorithm, the optimal response can be achieved in a short time. The genetic algorithm was successfully used in this optimization and the optimal design was calculated accurately. The optimal deck is obtained with the minimum possible weight, all the rules of the defined regulations and the minimum and maximum executive requirements of the designer [5].

\section{RESEARCH METHODS}

The bridges studied in this study are taken from the laboratory and numerical research of Mustafa and Moslem, which was conducted at the University of California, Berkeley and published by the PEER Institute [12]. The geometric plan of the study bridge with three spans with a height of 11.2 meters, as well as the reinforcement plan and material specifications, the mentioned research has been extracted and used for modeling. Figure 1 shows the longitudinal plan of the bridge.

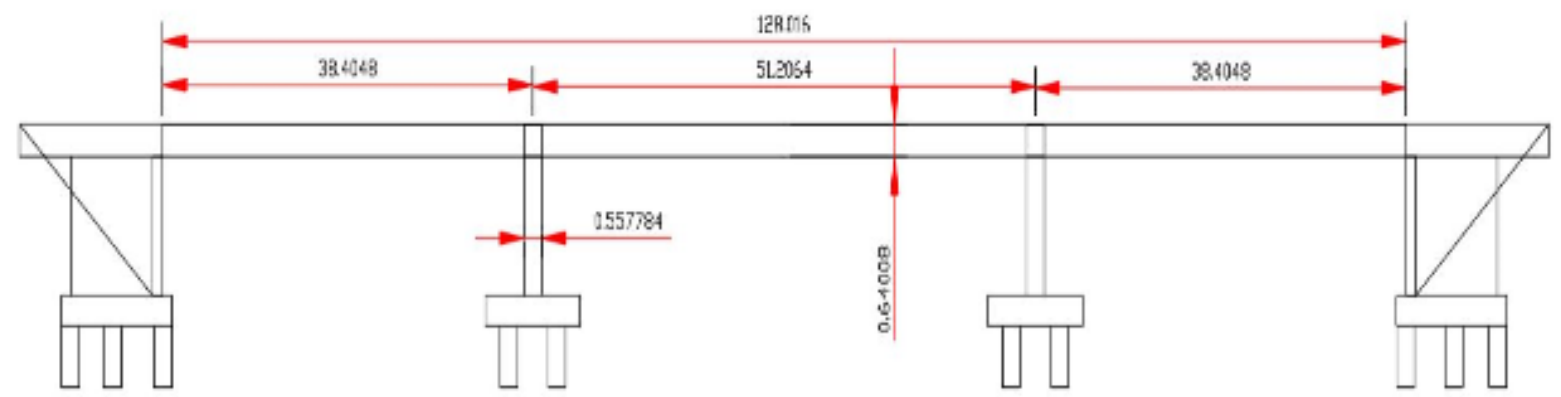

Figure1. Longitudinal plan (unit based on meters) \{Mohamed A. Moustafa\&amp; Khalid M. Mosalam 2015\} [12]

Also shown in Figure 2 is the cross section of the bridge deck.

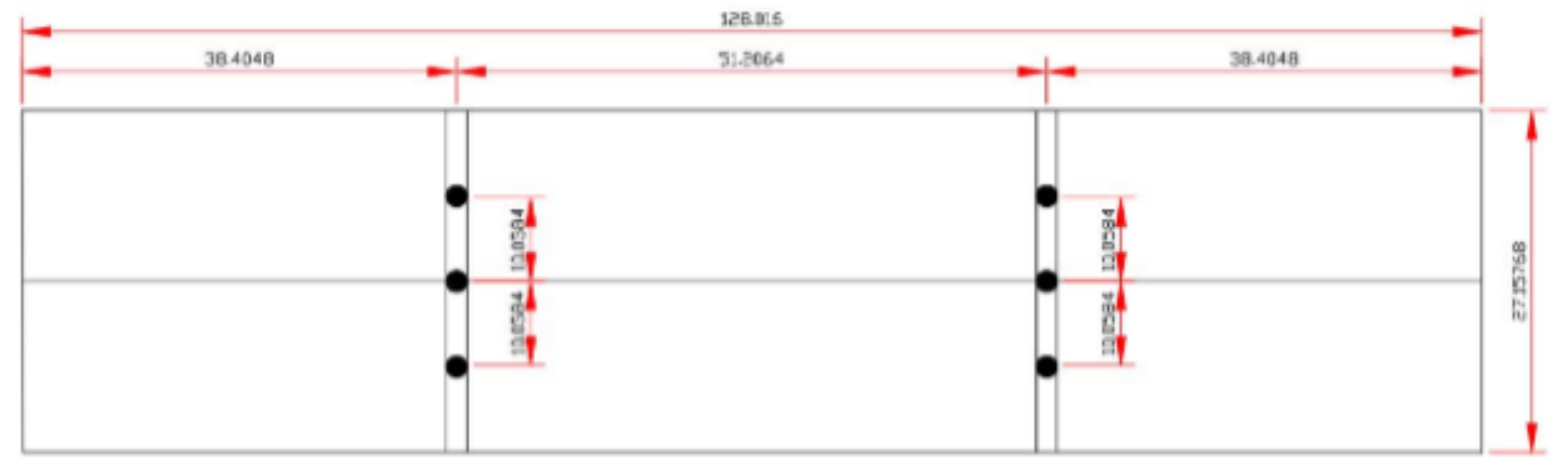

Figure2. Deck section (unit based on meters) \{Mohamed A. Moustafa\&amp; Khalid M. Mosalam 2015\} [12]

Figure 3 shows the cross section and its details.

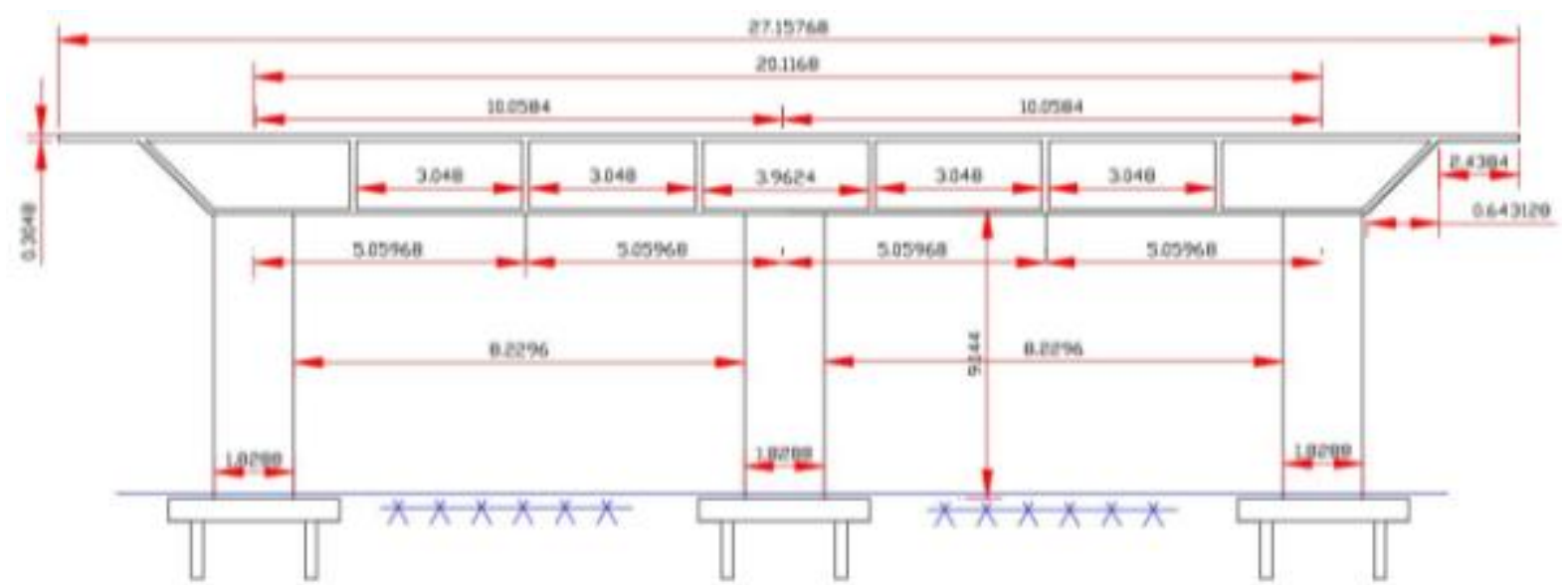

Figure3. Transverse plan (units in meters) \{Mohamed A. Moustafa\&amp; Khalid M. Mosalam 2015\} [12] 
Evaluation of the Parameters Affecting the Seismic Response of Railway Bridges with Reinforced Concrete Box Deck

The table1 give information's about section elements [dimension in Metric] [12]

Table1. Summarizes the sections of the elements \{Mohamed A. Moustafa\&amp; Khalid M. Mosalam 2015\} [12]

\begin{tabular}{|c|c|}
\hline Column Diameter & $5.5 \mathrm{M}$ \\
\hline Column Height & $27.5 \mathrm{M}$ \\
\hline Cap Beam/Superstructure Height & $6.1-1.2 \mathrm{M}$ \\
\hline Cap Beam Width & $7.3 \mathrm{M}$ \\
\hline Deck Slab Thickness & $0.6-1.5 \mathrm{M}$ \\
\hline Soffit Slab Thickness & $0.6-0.3 \mathrm{M}$ \\
\hline Box Girder Web Thichness & $1 \mathrm{M}$ \\
\hline Clear Width Of Box Cell & $9.2 \mathrm{M}$ \\
\hline Clear Height Of Box Cell & $5 \mathrm{M}$ \\
\hline Subassembly Overall Length & $80.5 \mathrm{M}$ \\
\hline Subassembly Overall Width & $31.1 \mathrm{M}$ \\
\hline
\end{tabular}

The table given below illustrate the summary of the specimen geometry [dimension in Metric] and reinforcement for column, Bent Cap and Box Girder. [12]

Table2. Summarizes reinforcement \{Mohamed A. Moustafa\&amp; Khalid M. Mosalam 2015\} [12]

\begin{tabular}{|c|c|}
\hline \multirow{2}{*}{ Column } & Longitudinal reinforcement \#6*16 \\
\hline & \#3 @ 2.5 in. (spiral) \\
\hline \multirow{3}{*}{ Bent Cap } & Positive reinforcement \#5*8 \\
\hline & Negative reinforcement $\# 5 * 8$ \\
\hline & \#3 strirrups @ 5 in. ( 4 branches ) \\
\hline \multirow{3}{*}{ Box girder } & \#3 @ 2.5 in. (transverse) \\
\hline & \#3 @ 2.5 in. (longitudinal) \\
\hline & \#3 @ 4 in. (single tie for web) \\
\hline
\end{tabular}

The bridge model in Abacus software in the part section was modeled in three-dimensional form. The model is modeled in three different dimensions: 2,3 and 4 openings. The length of the side openings is 38.4 meters and the length of the central openings is 51.6 meters. The height of the model is 11.2 meters and the width of the deck of the bridge is 1576/27 meters. The deck of the bridge was placed on three rows of columns at a distance of 8.2296 meters from each other. The model of the reinforcing rebar was modeled separately with Truss element and placed next to each other in the ASSMBLY section. The mechanical properties of the materials used in the modeling were defined and applied to the models according to the source mentioned in the table below. To identify the concrete and reinforcement properties the table 3 placed below. [12]

Table3. Mechanical specifications of materials \{Mohamed A. Moustafa\&amp; Khalid M. Mosalam 2015\} [12]

\begin{tabular}{|c|c|c|c|c|c|}
\hline $\begin{array}{c}\text { Transverse } \\
\text { rebar \#3 }\end{array}$ & $\begin{array}{c}\text { Longitudinal } \\
\text { rebar \#6 }\end{array}$ & $\begin{array}{c}\text { Longitudinal } \\
\text { rebar \#5 }\end{array}$ & $\begin{array}{c}\text { Longitudinal } \\
\text { rebar \#3 }\end{array}$ & concrete & \\
\hline 7880 & 7880 & 7880 & 7880 & 2400 & $(\mathrm{Kg} / \mathrm{m} 3)$ Density \\
\hline 193052 & 187351 & 176643 & 188800 & 31000 & Modulus of elasticity (Mpa) \\
\hline $3 / 0$ & $3 / 0$ & $3 / 0$ & $3 / 0$ & $2 / 0$ & Poisson's ratio \\
\hline $26 / 461$ & $67 / 475$ & $57 / 458$ & $5 / 464$ & - & Yield stress (Mpa) \\
\hline $61 / 719$ & $42 / 467$ & $76 / 671$ & $88 / 735$ & - & Ultimate Tension (Mpa) \\
\hline $1088 / 0$ & $1265 / 0$ & $0964 / 0$ & $1091 / 0$ & - & Ultimate strain \\
\hline- & - & - & - & $3 / 49$ & $\begin{array}{c}\text { Comprehensive strength } \\
\text { (Mpa) }\end{array}$ \\
\hline
\end{tabular}

A solid section for concrete was defined as solid and applied to the concrete section by the assign section. Also, sections were defined as truss by entering the cross-sectional area for rebar 20, 28, 32 and applied to the desired materials. In the Assembly section, the parts were assembled side by side. In the Step section, a frequency step was defined with the Lanczos solver and the software of the first 5 modes of the structure was requested. A 30-second Modal Dynamic Model Dynamic Solver was also defined with a time of 0.02 seconds, equivalent to the moments of the El Centro Earthquake 
Acceleration Diagram. In the interaction section, the reinforcing rebar were buried inside the concrete section by the embedded region order. In the LOAD section, the boundary conditions of the model were applied. In the initial section, both sides of the bridge and the foundations of the bridge at all degrees of freedom were bound by the ENCASTRE command. With the acceleration base motion command, the El Centro earthquake mapping was applied to the structure. The gravitational force was applied to the entire structure by gravity with a gravitational acceleration of 9.81 meters per second. In order to simulate the train load from the bridge, standard loading based on 139 publication has been used, which has been entered many times after the equivalent to the rail crossing on the deck of the bridge. In the mesh part of Abacus software, the models were modeled. The elements were determined as the optimal element and the size of the element should be between one and two times the concrete gravel. It was elementary. In the C3D4, the default networking priority will be with quadrilateral elements, but in transitional areas, triangular elements will also be present.

\section{RESUlT}

According to the displacement contours, the maximum displacement in the bridge with two spans of $10.53 \mathrm{~mm}$ in the bridge with three spans is $17.30 \mathrm{~mm}$ and in the bridge with 4 spans is $55.67 \mathrm{~mm}$. Therefore, it can be concluded that increasing the number of openings will increase the maximum displacement of bridges. In a bridge with two spans, the maximum displacement rate compared to the model with four spans of $193 \%$ increase in displacement was observed. In the three-span bridge, compared to the fourteenth bridge, an increase of $84.5 \%$ has been observed. Maximum displacements occurred in the middle openings of three-span and four-span bridges. Therefore, these areas are the most critical points on the stairs. As the bridge modes increase with the soot, the frequency of the structure also increases. Due to the relationship between frequency and period, increasing the vibrational modes of the bridge with soot will reduce the period of the structure. As the bridge modes increase, so does the frequency of the structure with three orifices. Due to the relationship between frequency and period, the structural period is reduced by increasing the vibrational modes of the bridge with three openings. Due to the Figure 4 It is found that as the modes of the bridge increase, so does the frequency of the structure with three orifices.

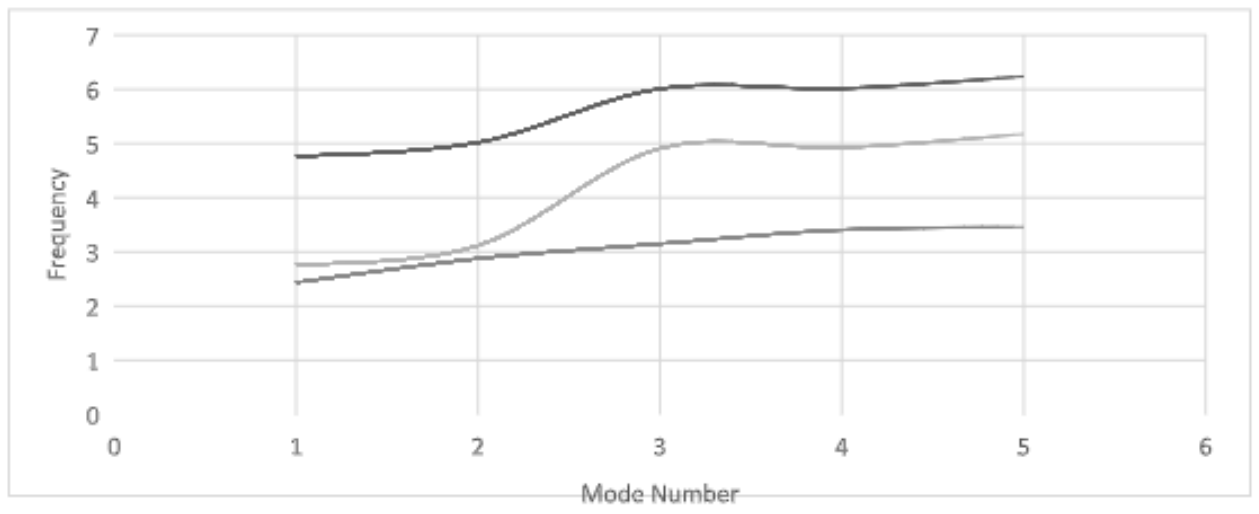

Figure4. Comparison of structural frequencies in the first 5 modes in bridges with two, three and four spans In the figure 5, the comparison of structural periods in the first 5 modes is presented in bridges with two, three and four openings.

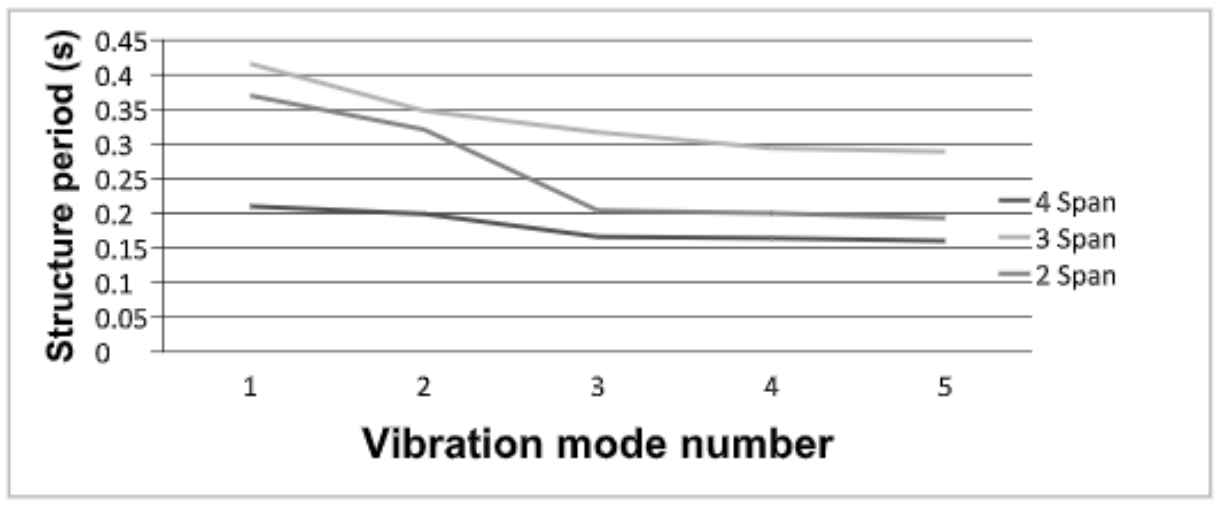

Figure5. Structure period in the first to fifth vibration modes in bridges with two, three and four openings 
According to Figure5 as the number of openings in all vibration modes increases, the period of the structure increases. It should also be noted that in all openings under study, the amount of structural period decreases with increasing vibration number. It should be noted that as the number of openings increases, the maximum amount of stress in the bridge will increase. In a bridge with two openings, the maximum stress level of Von Mises is $20.45 \mathrm{MPa}$, in a bridge with three openings, this rate is 21.33 MPa, and in a bridge with four openings, this rate is $41.25 \mathrm{MPa}$.

\section{InVESTIGATING THE EFFECT OF DIFFERENT BASE HEIGHTS}

In this study, three different base heights have also been studied. Elevations of 11.2, 8 and 5 meters in the bridge with three openings have been selected to investigate the effect of different base heights on the period and displacement of the bridge. It turns out that as the height of the pedestals increases, so does the displacement of the bridge. The maximum displacement of the bridge in the bridge with a base height of $11.2 \mathrm{~m}$ is observed to be $30.17 \mathrm{~mm}$. Also, this value is $1.17 \mathrm{~mm}$ in the bridge with a base height of $5 \mathrm{~m}$ and $2.75 \mathrm{~mm}$ in the bridge with a height of $8 \mathrm{~m}$. In the figure below, the periods of bridges with base heights of $2 / 11,5$ and 8 are presented.

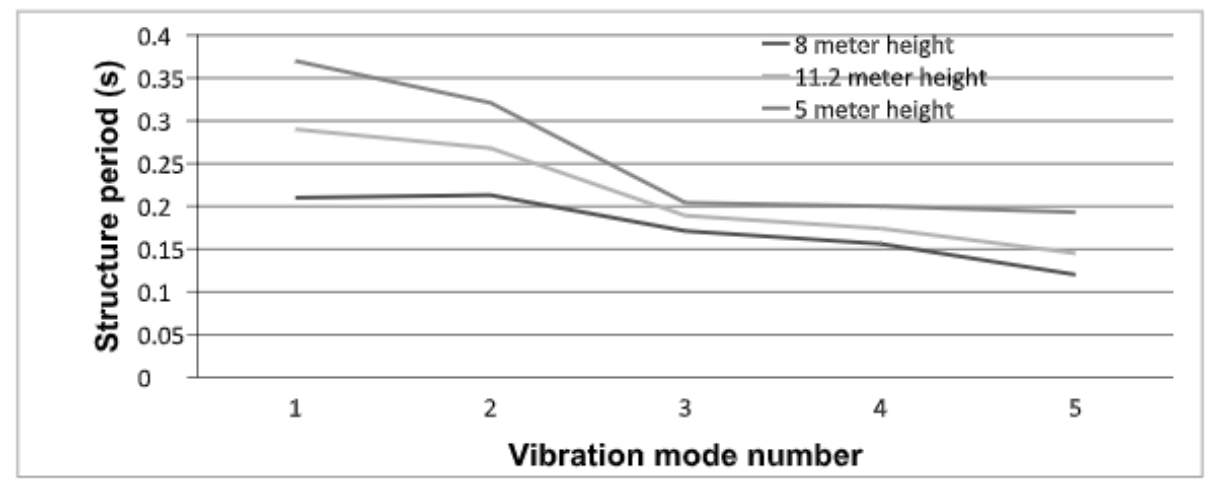

Figure6. Structure period in the first to fifth vibration modes at different base heights

According to Figure 6 in all vibration modes, increasing the height of the bases has increased the values of the bridge period. It should also be noted that at all different heights of the base, the amount of period decreases with increasing vibration mode number.

\section{DISCUSSION}

The study bridge extracted from the laboratory and numerical research of Mostafa and Mosalam is presented as 3 spans with a height of 11.2 meters, so that the initial and final spans are 38.4 meters long and the middle spans are 51.6 meters long. Re-modeling in Abacus software of the bridge was examined in 3 different lengths and heights, so that the bridge was 2 spans of 38.4 meters, then three spans, like the reference research bridge, and then 4 spans with the addition of an intermediate span with a length of $6 . / 51 \mathrm{~m}$ is checked, then, 3 reference springs were examined in three different heights of 5, 8 and 11.2 meters. The results showed that with the increase of spans, the displacement and maximum displacement of the bridge will increase so that the fourteen bridge has increased by $193 \%$ compared to the soot bridge and the displacement is more and more displacements are evident in the middle spans of the bridge. 3-span bridge at different heights was concluded that with increasing the height of the bridge from $5 \mathrm{~m}$ to $11.2 \mathrm{~m}$, the maximum displacement has been significantly increased to $29 \mathrm{~mm}$. It is important to note that rail bridges do not have the capacity to accommodate this amount of relocation, which can lead to accidents such as train derailment, structural damage to railway bridges and railways, as well as increased maintenance costs.

\section{CONCLuSion}

According to the displacement contours, the maximum displacement in the bridge with two spans of $10.53 \mathrm{~mm}$ in the bridge with three spans is $17.30 \mathrm{~mm}$ and in the bridge with 4 spans is $55.67 \mathrm{~mm}$. Therefore, it can be concluded that increasing the number of openings will increase the maximum displacement of bridges. In a bridge with two spans, the maximum displacement rate compared to the model with four spans of $193 \%$ increase in displacement was observed. In the three-span bridge, compared to the fourteen-span bridge, an increase of $84.5 \%$ has been observed. Maximum displacements occurred in the middle openings of three-span and four-span bridges. Therefore, these 
critical areas are considered as decorating points on the stairs. According to the research results, with increasing the number of openings in all vibrational modes, the structural period increases. It should also be noted that in all the studied openings, the amount of structural period decreases with increasing vibration number. On the other hand, with the increase in the height of the foundations, the amount of relocation of the bridge will increase. The maximum displacement of the bridge in the bridge with a base height of $11.2 \mathrm{~m}$ is observed to be $30.17 \mathrm{~mm}$. Also, this value is $1.17 \mathrm{~mm}$ in the bridge with a base height of $5 \mathrm{~m}$ and $2.75 \mathrm{~mm}$ in the bridge with a height of $8 \mathrm{~m}$. In all vibration modes, increasing the height of the bases has increased the values of the bridge period. It should also be noted that at all different heights of the base, the amount of period decreases with increasing vibration mode number.

\section{Data AVAILABILITY}

[12]- Moustafa, M. A., \&amp; Mosalam, K. M. (2015). Seismic response of bent caps in as-built and retrofitted reinforced concrete box-girder bridges. Engineering Structures, 98, 59-73. The data that support the findings of this study are openly available at http://dx.doi.org/10.1016/j.engstruct.2015.04.028

\section{REFERENCES}

[1] Tahouni, Sh and Khodaei, N., 2004, A Study of Deviation of Concrete Deck Bridges, First National Congress of Civil Engineering, Tehran, Sharif University, Civil Engineering.

[2] State Management and Planning Organization, Office of the Technical Executive System, \&quot; Collection and classification of damage to stairs in past earthquakes\&quot;, Journal No. 301, 2008

[3] Sayadpour, H. and Eftekhari, 2009, Sensitivity Analysis of Seismic Response of Concrete Bridge with Box Deck to Geometric and Mechanical Specifications, 11th National Congress of Civil Engineering, Shiraz, ShirazUniversity.

[4] Arabestani, Sh and Zarfam, P, 2018, Investigation of the effect of earthquake impact angle on the performance of box deck bridges with unequal bases, International Conference on Civil Engineering, Architecture and Urban Development Management in Iran, Tehran, Maragheh University of Technology in collaboration with Tabriz University - Shahid Madani University of Azerbaijan

[5] Naderpour, H.; Khair al-Din and Arab Naeini, M., 2014, Optimal design of prefabricated concrete stair deck boxes according to the loading regulations of Iran Bridge using genetic algorithm, Transportation Engineering Quarterly 6 (2).

[6] Keshtegar, B and Miri, M., 2009, Seismic Survey of Non-Linear Geometric Behavior of a Large Oral Cable Bridge, with box deck, according to the angle of impact of seismic waves, 8th International Congress of Civil Engineering, Shiraz, Shiraz University.

[7] Fazeh, M. and Moharremi, H., 2011, The effect of the vertical earthquake component on two-span railway bridges in areas near the fault, 6th International Conference on Seismology and Earthquake Engineering, Tehran, International Institute of Seismology and Earthquake Engineering

[8] M. Abbasi, B. Zakeri, G.G. Amiri, Probabilistic seismic assessment of multiframe concrete box-girder bridges with unequal-height piers, Journal of Performance of Constructed Facilities, 30(2) (2015) 04015016

[9] J. Jara, J. Reynoso, B. Olmos, M. Jara, Expected seismic performance of irregular medium-span simply supported bridges on soft and hard soils, Engineering Structures, 98 (2015) 174-185.

[10] Gupta, T., \&amp; Kumar, M. (2018). Flexural response of skew-curved concrete box-girder bridges. Engineering Structures, 163, 358-372.

[11] Ahmed, G. H., \&amp; Aziz, O. Q. (2019). Shear behavior of dry and epoxied joints in precast concrete segmental box girder bridges under direct shear loading. Engineering Structures, 182, 89-100

[12] Moustafa, M. A., \&amp; Mosalam, K. M. (2015). Seismic response of bent caps in as-built and retrofitted reinforced concrete box-girder bridges. Engineering Structures, 98, 59-73.

[13] Dassault Systemes to acquire Abaqus Inc for $413 \mathrm{mln}$ usd cash\&quot;. 17 May 2005. Retrieved 7 July

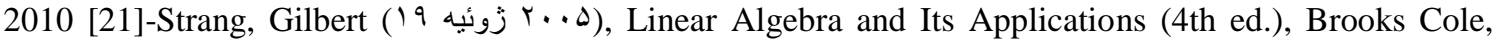
ISBN 978-0- 03-010567-8

[14] Preliminary Earthquake Reconnaissance Report on the June 22, 2002 Changureh (Avaj), Iran Earthquake;. International Institute of Earthquake Engineering and Seismology. 2002-07-19. Archived from the original on March 25, 2010. Ret

[15] Research Center of the Islamic Consultative Assembly \&quot;20-Year Perspective of Iran\&quot; 2005. 
Evaluation of the Parameters Affecting the Seismic Response of Railway Bridges with Reinforced Concrete Box Deck

[16] The official website of the International Institute of Seismology and Earthquake Engineering of Iran: http://www.iiees.ac.ir

[17] Vice President for Strategic Oversight, Office of the Executive Technical System, \&quot;Guide to Improving Seismicity of Bridges; Journal No. 511, 2011

[18] Akbari, Reza, 2012, Inspection of concrete bridges with boxed junctions, Road Quarterly 27(71)

[19] Group of Stairs and Passages of the General Directorate of Railways and Technical Structures of Railways, General Statistics of Iranian Railway Bridges, 2018

[20] Tahouni, Sh., 2012, Bridge Design: Reinforced and Steel Reinforced Concrete Bridges, Third Edition, University of Tehran Press.

[21] Website of Iran International Institute of Earthquake and Earthquake Engineering: http://www.iiees.ac.ir

[22] Dynamic Behavior of Seismic Polymer Boxes of Arm Concrete Box Deck, 5th National Conference on Self-Compact Concrete of Iran and First National Conference on Maintenance of Concrete Structures, Tehran, Alam University and Iranian industry.

Citation: Moein Zargar, Mohammad Ali Rahgozar, "Evaluation of the Parameters Affecting the Seismic Response of Railway Bridges with Reinforced Concrete Box Deck”, International Journal of Constructive Research in Civil Engineering, 6(2), pp. 38-45 DOI: https:// doi.org/10.20431/2454-8693.0602004.

Copyright: (C) 2020 Authors, This is an open-access article distributed under the terms of the Creative Commons Attribution License, which permits unrestricted use, distribution, and reproduction in any medium, provided the original author and source are credited. 